\title{
Study on the Construction of Intelligent City in Big Data Era
}

\author{
Bin Zhang
}

School of Geo-spatial Information, Information Engineering University, Zhengzhou Henan, 450052, China

Key words: Big data, Intelligent city, Countermeasure.

\begin{abstract}
Through the development of the past years, the construction of the intelligent city in our country grows extremely fast, and the governments at all levels have deeply felt the charm of the intelligent city. It plays a very positive role in improving the governance capacity of all government departments, improving the public service capacity of cities, improving the industrial structure as well as the citizens' happiness in their cities. From the city layout, land planning to urban operation and management, to the decision-making of local government departments, large data has been gradually integrated into all aspects of the intelligent of the city. Big data, the catalyst, penetrate into the intelligent of the city, to promote the intelligent of the city at a faster pace to develop. On the basis of defining relevant concepts, this paper analyzes the current situation of the construction of the intelligent city, expounds the concrete application of the big data in the intelligent city of our country, and puts forward the strategies of the intelligent city construction in the big data era.
\end{abstract}

\section{Introduction}

The current people's living standards in the urbanization process has been continuously improved, but also produced a variety of social problems to affect the development of urban construction, information technology has been greatly developed in the moment, we must regard the data as very important Of the factors of production, the urbanization, industrialization and information technology combined, which requires the full application of new technologies and new means to alleviate the above problems. To the Internet of Things and cloud computing and other large data technology as the center of the modern intelligent of urban construction concept, has become the future development of a new model of the city. Smart city can be said that human society in the development to a certain stage after an inevitable product. Through the implementation of the creation of smart city, can better solve the problems faced by urban development, which can improve the ability of urban information management, to promote the development of China's high-end industries. In the process of building a smart city, there will certainly be huge amounts of data, which requires the use of large data to show the intelligent of the infinite power of the city, which for the future to further improve the city's public service capabilities and promote their own development has important significance.

\section{Related Concepts Definition}

The so-called era of large data, that is, high-tech era, its main feature is the social development into the era of high-speed information, people's lives have become more and more convenient. In the era of large data comes, are usually and cloud computing can not distinguish. It is because of the emergence of cloud computing technology, guiding the modern city into the era of large data. In the current era, the modern people have gradually felt the benefits of large data, its advantages are being affirmed, but also gradually deep into the whole society, among many industries. Because cloud computing technology has been a great use, and the advantages of large data can also be fully developed. As a result, network companies can quickly grasp the many users on the network implementation of information on the gathering, so as to enable the implementation of a comprehensive analysis of user groups in order to promote the Internet business to achieve new development. The so-called smart city, mainly refers to the rapid development of modern information technology, the use of high-tech means to bring together human intelligent, so that it can implement 
the integration of the city, so that it can achieve intelligent. In the city, on the basis of continuous development, also appeared in the use of resources, environmental protection and population conflicts and many other problems may be solved. In this situation, some researchers put forward the idea of building a smart city. Smart city is a new generation of information technology to be used on the basis of the city to solve many problems. Including the cloud of scientific and technological means, will be able to effectively help the city to integrate all kinds of resources, so as to actively create a highly efficient city and promote the continuous development of the city.

\section{Analysis on Current Situation of Intelligent City Construction}

The intelligent city is the important development trend of our country 's cities in the future. Since 2013, the national housing construction has been announced three batches of smart city pilot list, of which the pilot city reached more than 300. Through three years of continuous development, China's smart city construction has made great progress, the city's investment is also very large, very deep understanding of government departments to create a smart city in the deepening urbanization and upgrading government capacity to improve the industry Structure and improve people's well-being and many other aspects have a very positive role. However, the construction of China's smart city is still facing the following four aspects: First, many local governments for the lack of understanding of the intelligent of the city, but the use of old thinking to create a smart city, as the traditional sense of the project Secondly, the proportion of infrastructure in the creation of the current intelligent of the city is too large, that only need to pull a few network lines, security camera is equal to a few smart city, while ignoring the intelligent of the city among the software factors; Thirdly, it is unable to fully integrate the information systems of many departments of the city, resulting in the phenomenon of data island becoming so serious that it can not enhance the management ability and public service capacity of the local government. Finally, it regards the intelligent city as image project and even Is the performance engineering, ignoring the actual needs of the market, so that government investment in resources has been greatly wasted.

\section{The Application of Big Data in China 's Intelligent Cities}

First, one of the applications is the intelligent economy. Big data can be analyzed through the commercial level of the user's various shopping behavior, which goods with each other in order to achieve the best results. There are a large number of enterprises to use large data to find the best customers. Taobao data cube Taobao platform is a large data practice example. Businesses can understand the Taobao platform to the industry through the integrated status of its own brand market conditions, customer behavior, etc., but also the implementation of business decisions accordingly. By collecting information, companies can have an excellent grasp of their own operations, analysis of Internet users and financial-related records, for example, can apply for loans and leases, retail purchase of goods, utilities to pay, digital TV and telephone payment, Press subscriptions, etc., so as to come to the customer's personal credit situation, and then be able to infer the customer's intention and ability to pay. The second is the intelligent of governance. Use micro-Bo, WeChat and search engines, etc., to collect a large number of hot events and public opinions. Telecom operators have a lot of mobile phone data, can be applied to the mobile phone data to be excavated, can grasp the real-time, dynamic population of the source and distribution of the situation. Third, it also can be used in environmental monitoring. City rivers can be sampled and satellite-derived data collected. The amount of such data is extremely large, and the data can be used to determine the extent to which the city has low to no pollution and pollution. Fourth, it is about the intelligent and medical treatment. Whether the drug development, or build business model, the use of data analysis can be a good analysis of the results. There are many cases of hospital, including a lot of data. In the past, it was difficult to excavate the corresponding data in common cases, which is very helpful to promote the discovery of data, but also very beneficial to master the medical knowledge. At the same time, can 
also be applied to family medical services, in chronic disease and sub-health management of large data also has a great role. Fifth will be the intelligent transportation. Depending on the large data platform of the smart city, advanced information, communication, sensing and computer technology should be integrated, used in transportation systems, and be able to fully utilize large data to deal with violation penalties, vehicle tracking and traffic flow Control and other applications, the formation of intelligent traffic information platform, based on the road traffic information on the implementation of data analysis, the use of platform for the public to publish, thereby effectively reducing traffic loads and environmental pollution, to ensure traffic safety, And then the success of the transport. Sixth, it can be used in intelligent education. This refers to the government-led, by the school and with the enterprise to participate in the creation of modern education information system. The system is mainly composed of cloud computing, Internet of things, the Internet, digital educational resources and cloud equipment and other components. Everyone can use cloud equipment at all times and locations to personalize and learn.

\section{The Strategies of Intelligent City Construction in Big Data Era}

\section{Enhance the development and sharing of information resources}

On the one hand to continually promote the sharing of information resources and updates. To actively collect the database of resources in the city, and continuously promote the intelligent of the city data sharing platform for the creation of work, but also should continue to improve the platform for information sharing system. Different industries should be in accordance with the scope of authorization, rational use of good sharing of information resources to promote network management. On the other hand is to continuously improve the development and utilization of information resources. To continue to promote China's government departments to product safety and quality, public facilities construction and integrated transport to the city tends to intelligent.

\section{Encourage people to participate in the actual urban construction}

The ultimate goal of creating a smart city is to enhance the quality of life of the general public and the city's actual governance capacity. The capital of intelligent urban construction comes from the tax paid by the people. How to protect the intelligent of the city can really serve the people? Western countries, urban construction, pay great attention to the adoption of the recommendations made by the people. Residents living in the community not only understand the needs of life, but also very familiar with the actual situation of urban operation. Therefore, in the course of developing the city of intelligent, the city managers should take the initiative to ask the community residents for the intelligent of the city's valuable suggestions to ensure that urban construction planning can be reasonable, feasible and effective.

\section{Actively promote the construction of intellectual industry}

To actively targeting the intelligent of the city building in the implication of the huge market, more scientific positioning of the intelligent of the general direction of industrial development, analysis of the next step in the development of ideas, set the scale of the intelligent of urban construction industry support fund, active and venture capital institutions and financial Institutions and other cooperation, and constantly expand the scale of the fund, so that the chain of funds can be configured around the chain of innovation. The establishment of the intelligent of the city industrial development incubator and industrial park, the full integration of various types of industry, academia, research and other forces, to establish a smart industry innovation alliance, and continuously enhance the intelligent of industry innovation, and around the chain to configure the corresponding innovation chain , To promote China's intelligent into the city-related industries, high-end, to promote enterprises to the direction of the intelligent of the industry to be transformed. 


\section{Accelerate the pace of talented personnel training in the intelligent cities}

With the intelligent of urban construction continues to advance, will certainly bring big data of continuous progress. As early as in 2011, the Ministry of Industry and Information Technology in the introduction of the 12th Five-Year Plan when the information processing technology will be regarded as an important one of the four key technological innovation projects have been proposed, which covers massive data storage, image Video and other intelligent analysis technology, these are large data is extremely important part of one. Because of our country for large data research is still in its infancy, the large data should be how to deal with and analysis of the ability to lag behind. Therefore, in the process of creating a smart city, the government should be the main body, the effective integration of enterprises and institutions of higher learning among the various types of human resources, and fully cultivate large data-related professionals, and to explore and actively learn from Western countries Advanced Theory Knowledge of Intelligent City Construction. Government departments or enterprises should also strive to introduce foreign advanced technology and the introduction of talent, so as to build a smart city to provide more adequate technical support. To actively introduce and cultivate large data professionals, according to the needs of targeted introduction of high-level personnel, and effectively play a leading role, so that the role of human resources can play to the greatest extent, and then explore the large data The field of high, refined, cutting-edge talent, to further enhance the introduction of the treatment of talent, and its contribution to the corresponding substantial rewards. At the same time, it is necessary to actively cultivate technical talents for large data fields. In recent years, people pay more attention to big data, and the demand for large data talents has become more and more, so the training of large data professionals has been paid more and more attention. Some colleges and universities have set up a large data class of professional courses, but still difficult to meet the current actual needs. To this end, the local government and institutions of higher levels learn to work together to create a large data professionals training mechanism.

\section{Conclusion}

Overall, China's intelligent city construction is the original city in the management of the transformation and upgrading, it can be said is a qualitative leap, not only limited to large data, but also benefit from the large data. The synergy between Smart City and Big Data can drive the constant change and innovation of information systems. The intelligent city is the future form of our country's urban development. Today, China is still in the intelligent of the initial stage of development of urban construction. Big data is a very important factor to promote social development, not only for the development of China's intelligent to provide great support for the city, but also for the intelligent of the city to provide technical support. Big data is not only from the intelligent of the city, but also for the intelligent of the city's sustainable development to provide strong support. Facing the era of large data, only continue to deepen the intelligent of urban construction-related technology, to be able to create a smart city in the process of success.

\section{Acknowledgement}

This paper is supported by Key Laboratory Fund Project of Tianjin Normal University. Project Name: Research on Key Technologies of Data Mining Based on Location Service, No: 07021102.

\section{References}

[1] Wu Hechuan. Intelligent City Generates Big Data and Big Data Supports Intelligent City. Journal of Computer Software and Software, 2013 (22). 
[2] Zhu Yajie, Li Qi, Feng Xiao. Study on the Architecture of Intelligent City Technology System Based on Large Data. Science of Surveying and Mapping, 2014 (8).

[3] Li Deren. Big Data in Intelligent Cities. Wuhan University Journal (Information Science Edition), 2014 (6)

[4] Ning Jiajun. Mining Big Data in Large Intelligent Cities. China's Economy and Information Technology, 2014 (14).

[5] Tao Xujun. Intelligent City in the Background of Big Data. Mobile Communications, 2014 (21).

[6] Li Chuanjun. Data Technology and Intelligent City Construction. Journal of Tianjin Administration Institute, 2015 (4).

[7] Wang Fengyun, Chen Yannan. The Construction Intellectual Cities in the Era of Big Data and Development Dilemma. Shanghai Urban Management, 2016 (2). 